\title{
Association between Molar Incisor Hypomineralization and Both Prenatal and Postnatal Factors in 8-10-Year-Old Children in Ardebil
}

\author{
Majid Einollahi ${ }^{1}$, Somayeh Hekmatfar², Mahsa Molaei $^{3}$ \\ ${ }^{1,3}$ Department of Orthodontics, School of Dentistry, Ardabil University of Medical Sciences, Ardabil, Iran. \\ ${ }^{2}$ Department of Paediatric Dentistry, School of Dentistry Ardabil University of Medical Sciences, Ardabil, Iran.
}

\section{ABSTRACT}

\section{BACKGROUND}

Molar incisor hypo-mineralization is a malformation with a systemic background for which aetiology is not well defined. Prevalence of these lesions varies in different countries, but few studies have been conducted on its prevalence in the Iranian society. The aim of this study was to determine the prevalence of molar incisor hypomineralization among 8-10-year-old children in Ardabil and its relationship with prenatal and postnatal factors.

\section{METHODS}

In this analytical cross-sectional study, participants included 520 children from public schools of Ardabil. In the first stage, the frequency of MIH was determined by a clinical examination based on the index introduced by Tourino et al. Then, they were evaluated in two groups (with or without incisor hypo mineralization) to determine the causative factors. To collect information, a questionnaire including information about factors before and after birth was used. Data were analysed using SPSS 18 software. Chi-square and T-test and logistic regression were used to test the relationship between different factors.

\section{RESULTS}

The prevalence of molar-incisor hypo mineralization in children aged 8-10-year-old in Ardabil was estimated to be $24 \%$. The results also showed that there is a significant relationship between prenatal and postnatal factors $(\mathrm{p}<0.05)$.

\section{CONCLUSIONS}

Due to the high prevalence of MIH in Ardabil, preventive measures, informing the parents and periodic examination of the teeth are recommended.
Corresponding Author

Mahsa Molaei,

Department of Orthodontics,

School of Dentistry,

Ardabil University of Medical Sciences,

Ardabil, Iran.

E-mail:m.molaei@arums.ac.ir

DOI: $10.14260 /$ jemds/2020/793

How to Cite This Article:

Einollahi M, Hekmatfar S, Molaei M. Association between molar incisor hypomineralization and both prenatal and postnatal factors in 8-10 year old children in ardebil. $J$ Evolution Med Dent Sci 2020;9(48):3606-3610, 10.14260/jemds/2020/793

Submission 26-12-2019,

Peer Review 15-10-2020,

Acceptance 21-10-2020,

Published 30-11-2020.

Copyright (C) 2020 JEMDS. This is an open access article distributed under Creative Commons Attribution License [Attribution 4.0 International (CC BY 4.0)]

\section{KEY WORDS}

MIH, Prevalence, Aetiology 


\section{BACKGROUND}

Molar-Incisor Hypomineralisation (MIH) is characterized by asymmetric opacities with a systemic origin, affecting one to four permanent first molars, which can manifest themselves in anterior permanent teeth. ${ }^{1}$

MIH was first introduced as a new type of enamel lesion by Koch, and then the term MIH was used by Weerheijm in 2001, meaning a type of developmental defect in enamel and hypomineralization with systemic origin ${ }^{2}$ The prevalence of MIH in different populations varies depending on the age of the subjects, methodological differences and the criteria used in diagnosis. Studies show that the lowest prevalence is observed among Chinese children $(2.5 \%) .^{3}$ Tourino et al's study (2016) on 1181 Brazilian children estimated the prevalence of MIH to be $20.4 \% .4$ In 2013, Garcia et al., conducted a study on 840, 9-year-old children from Spain and reached to the conclusion that the prevalence of MIH was about $21.8 \%{ }^{5}$ Ahmadi et al. (2012) investigated the prevalence of MIH on 433 children aged 7 - 9 in Zahedan. ${ }^{6}$ The prevalence of MIH was about $12.7 \%$. Although its aetiology is not yet well understood, the evidence suggests that systemic factors affect the lesions at different stages of tooth development. Enamel formation of the permanent first molar begins from the $28^{\text {th }}$ week of the embryo until the first ten days of birth. Given that ameloblasts are the most sensitive cells in the body, any slight changes in the environment can cause temporary or permanent damage to them and may cause hypoplasia (damage to the matrix formation) or hypomineralisation (damage at calcification or maturation stage). Among the possible causes, type of delivery and its associated problems such as fever and decreased oxygen supply to the mother or child's tissues, respiratory infections, low birth weight, and electrolyte imbalance in premature infants, calcium and phosphorus metabolism disorders, and diseases repeated during the first three years of life, antibiotic consumption, as well as the combination of several aetiologic agents that reinforce each other can be mentioned.6-8 However, geographical differences can address the role of genetics in its aetiology to explain the prevalence of MIH and the indefinite reason of the lesions. ${ }^{9}$ Although many studies have investigated the potential factors involved in the occurrence of $\mathrm{MIH}$, the findings are mixed and contradictory. 4,6,10 Due to the uncertainty of prenatal and postnatal factors in the prevalence of $\mathrm{MIH}$, this study aimed to investigate the prevalence of MIH among 8-10-year-old children in Ardabil and its relationship with prenatal and postnatal factors in Ardabil schools during 2018 - 2019.

\section{METHODS}

This research was an analytical cross-sectional study in two stages. The population was 8 - 10 years old children from primary schools in Ardabil, Iran. In the first phase of the study, because there is a wide variation in the socioeconomic conditions of the population in different areas of the city, the city was classified into 4 zones, north, south, east and west, and 4 schools were randomly selected in each zone. In each school, based on student numbers, 30 - 35 students were randomly chosen and examined. According to Salem et al. (2016) and other previous studies, the $95 \%$ confidence interval with 2.5 $\%$ error rate was considered and final sample size calculated was 520.11 Inclusion criteria included: children aged 8 to 10 years and willingness to cooperate with examinations. The consent form were taken from children or their parents before any examination. Exclusion criteria included: 1 . The presence of enamel or dentin lesions in all teeth or a number of them done based on the specific diagnostic criteria for such lesions (Amelogenesis imperfecta, dentinogenesis imperfecta, and fluorosis). 2. Chronic hypoplasia, such as a history of infection or trauma to the anterior teeth. All dental examinations conducted in the schools using a headlight, and flat dental mirrors. After cleaning the teeth (permanent first molars and maxillary and mandibular incisors) with gauze, the wet teeth were examined by a calibrated examiner to investigate opaque stains and surface damage. Enamel defects are determined as follows:

\section{Grade 1 Lesions}

Discoloration from white, milky to yellowish-brown in the upper part with a clear border less than $2 \mathrm{~mm}$.

\section{Grade 2 Lesions}

Tooth decay; enamel defect indicating loss of tissue after tooth eruption; this is often associated with opacity.

\section{Grade 3 Lesions}

Unusual restoration; the size and shape of the restoration are inconsistent with the usual appearance of caries. In most cases, restorations that extend to buccal and palatal surfaces are found in the molar. Opacity is often observed on the margin of restoration. In incisor teeth, buccal restorations are unrelated to trauma. ${ }^{12,13}$

From 520 children who were examined 125 subjects were diagnosed as MIH. In order to complete the second phase of the study, the students selected as MIH for the first stage were considered the case group. The control group participants were the same age children studying in the same school and class. Children with the diagnosed disorders were compared with healthy children. The research checklist completed by both groups included demographic questions and questions about possible intervening factors in lesions including prenatal factors such as preeclampsia, medicine consumption to prevent premature labour, paracetamol use (Acetaminophen), premature birth, oxygen device without intubation, and postnatal factors including duration of breastfeeding, illness up to age 4, pneumonia, asthma / bronchitis, antibiotics consumption, analgesics, asthma medication, history of hospitalization and fever above $38.5^{\circ} \mathrm{C}$. Mothers were given the opportunity to re-announce items other than the questions raised.

\section{Statistical Analysis}

The statistical analysis methods of chi-square for qualitative variables, fisher test to multivariable factors and logistic 
regression to show correlation between variables were done using SPSS version 23 (IBM SPSS Statistics 23).

\section{RESULTS}

The sample comprised of 242 (46.7\%) male and 278 (53.3\%) females. The results of this study showed that the prevalence of MIH among children aged 8 - 10 years old in Ardabil is $24 \%$. However, the chi-square statistics did not reveal any significant differences between boys (25.2\%) and girls (23\%) $(\mathrm{p}=0.316)$ ). The results of chi-square test showed that prenatal factors did not affect the prevalence of MIH in 8 - 10 year-old children in Ardabil ( $p>0.05$ ) (Table 1).

\begin{tabular}{|c|c|c|c|c|c|c|c|c|}
\hline & \multicolumn{2}{|l|}{ Factors } & \multicolumn{2}{|c|}{ Affected } & \multicolumn{2}{|c|}{ Unaffected } & \multirow{3}{*}{$\begin{array}{c}\begin{array}{c}\text { Chi- } \\
\text { Square }\end{array} \\
0.635\end{array}$} & \multirow{3}{*}{$\begin{array}{c}\text { P- } \\
\text { Value } \\
0.577\end{array}$} \\
\hline \multirow{10}{*}{$\begin{array}{l}\text { Prenatal } \\
\text { Factors }\end{array}$} & Droclamncis & Yes & 0 & 0 & 0 & $0 \%$ & & \\
\hline & \multirow{3}{*}{$\begin{array}{c}\text { Taking medicine to } \\
\text { prevent premature } \\
\text { labour }\end{array}$} & No & 125 & $24.1 \%$ & 395 & $75.9 \%$ & & \\
\hline & & Yes & 6 & $20 \%$ & 24 & $80 \%$ & \multirow[b]{2}{*}{0.284} & \multirow[b]{2}{*}{0.389} \\
\hline & & No & 119 & $24.3 \%$ & 371 & $75.7 \%$ & & \\
\hline & \multirow{2}{*}{$\begin{array}{c}\text { Taking } \\
\text { paracetamol } \\
\text { (acetaminophen) }\end{array}$} & Yes & 20 & $26.7 \%$ & 55 & $73.3 \%$ & \multirow[b]{2}{*}{0.332} & \multirow[b]{2}{*}{0.328} \\
\hline & & No & 105 & $23.6 \%$ & 340 & $76.4 \%$ & & \\
\hline & \multirow{2}{*}{ Premature birth } & Yes & 7 & $17.9 \%$ & 32 & $82.1 \%$ & \multirow{2}{*}{0.856} & \multirow{2}{*}{0.237} \\
\hline & & No & 118 & $24.5 \%$ & 363 & $75.5 \%$ & & \\
\hline & \multirow{2}{*}{$\begin{array}{l}\text { Using oxygen } \\
\text { device without } \\
\text { intubation }\end{array}$} & Yes & 2 & $66.7 \%$ & 1 & $33.3 \%$ & \multirow[b]{2}{*}{3} & \multirow[b]{2}{*}{0.145} \\
\hline & & No & 123 & $23.8 \%$ & 394 & $76.2 \%$ & & \\
\hline \multicolumn{9}{|c|}{ ct of Prenatal Factors on MIH } \\
\hline
\end{tabular}

\begin{tabular}{|c|c|c|c|c|c|c|c|c|}
\hline & Factors & & & ected & Una & ffected & $\begin{array}{l}\text { Chi- } \\
\text { Square }\end{array}$ & $\begin{array}{c}\text { P- } \\
\text { Value }\end{array}$ \\
\hline & Breastfeeding more & Yes & 105 & $24.2 \%$ & 329 & $75.8 \%$ & & \\
\hline & than 6 months & No & 20 & $23.3 \%$ & 66 & $76.7 \%$ & 0.035 & $48 /$ \\
\hline & Breastfeeding less & Yes & 16 & $32.7 \%$ & 33 & $67.3 \%$ & 2109 & 0098 \\
\hline & than & No & 109 & $23.1 \%$ & 362 & $76.9 \%$ & 2.199 & 0.09 \\
\hline & Disease up to 4 years & Yes & 13 & $31 \%$ & 29 & $69 \%$ & 120 & 0181 \\
\hline & & No & 112 & $23.4 \%$ & 366 & $76.6 \%$ & 1.20 & $0.10 \mathrm{c}-\mathrm{C}$ \\
\hline & Рneumonia & Yes & 7 & $46.7 \%$ & 8 & $53.3 \%$ & 433 & 0044 \\
\hline & Pneumonia & No & 118 & $23.4 \%$ & 387 & $76.6 \%$ & 4.33 & 0.044 \\
\hline & The effect of asthma / & Yes & 9 & $64.3 \%$ & 5 & $35.7 \%$ & 1276 & 0001 \\
\hline di & hro & No & 116 & $22.9 \%$ & 390 & $77.1 \%$ & 12.70 & $0.00 \mathrm{c}-2 \mathrm{C}$ \\
\hline & Use of antihiotics & Yes & 41 & $31.3 \%$ & 90 & $68.7 \%$ & 054 & 0018 \\
\hline & & No & 84 & $21.6 \%$ & 305 & $78.4 \%$ & & \\
\hline & Use of analoesics & Yes & 32 & $33 \%$ & 67 & $67 \%$ & 023 & 0017 \\
\hline & & No & 93 & $22.1 \%$ & 328 & $77.9 \%$ & & \\
\hline & Taking medication for & Yes & 10 & $58.8 \%$ & 7 & $41.2 \%$ & 164 & 0002 \\
\hline & & No & 115 & $22.9 \%$ & 388 & $77.1 \%$ & 1.64 & 0.002 \\
\hline & The history of & Yes & 42 & $35.6 \%$ & 76 & $64.4 \%$ & 116 & 0001 \\
\hline & hospitalization & No & 83 & $20.6 \%$ & 319 & $79.4 \%$ & 11.16 & \\
\hline & bove 385 > & Yes & 47 & $34.1 \%$ & 91 & $65.9 \%$ & 133 & 010 \\
\hline & rever adove $38.3 \mathrm{c}$ & No & 78 & $20.4 \%$ & 304 & $79.6 \%$ & 11.33 & 0.001 \\
\hline
\end{tabular}

\begin{tabular}{|cccccccc|}
\hline $\begin{array}{c}\text { The Variables } \\
\text { Remained in the } \\
\text { Model }\end{array}$ & Beta & $\begin{array}{c}95 \% \\
\text { Confidence } \\
\text { Interval }\end{array}$ & $\begin{array}{c}\text { Valid } \\
\text { Statistics }\end{array}$ & DF & $\begin{array}{c}\text { Odds } \\
\text { Ratio }\end{array}$ & $\begin{array}{c}\text { P- } \\
\text { Value }\end{array}$ \\
\hline Asthma / bronchitis & $\begin{array}{c}0.524 \\
1\end{array}$ & 0.580 & 6.906 & 1 & 6.20 & 0.009 \\
$\begin{array}{c}\text { The history of } \\
\text { hospitalization }\end{array}$ & $\begin{array}{c}0.500 \\
0\end{array}$ & 0.251 & 3.985 & 1 & 1.19 & 00.46 \\
Fever above 38.5 C & $\begin{array}{c}0.466 \\
0\end{array}$ & 0.241 & 3.844 & 1 & 1.24 & 0.049 \\
\hline Contingency coefficient & $\begin{array}{c}0.471 \\
-1\end{array}$ & 0.136 & 117.75 & 1 & 0.34 & 0.000 \\
\hline Table 3. Results of Multivariate Logistic Regression & \\
\hline
\end{tabular}

As it is shown in table 2 the results of postnatal factors on the prevalence of MIH showed that factors such as pneumonia, asthma / bronchitis, antibiotics consumption, analgesics, asthma medication, history of hospitalization and fever above 38.5 C had a significant effect on the prevalence of MIH ( $\mathrm{p}<$ 0.05). Therefore, these variables were entered into the multiple logistic regression model as a predictor variable for MIH. A total of 520 people were included in the analysis.

Multiple logistic regression results showed that only the variables of asthma / bronchitis, hospitalization history, and fever above $38.5 \mathrm{C}$ could predict MIH $(\mathrm{p}<0.05)$ (Table 3 ).

\section{DISCUSSION}

In this descriptive-analytic study, prevalence of MIH among 810 -year-old children in Ardabil was $24 \%$. In three other Iranian studies published by Ahmadi et al (2012) in Zahedan, the prevalence of MIH in 433 children aged 7 to 9 years was $7.12 \% .^{6}$ Ghanim et al (2013) conducted a study on 810 children aged 9 to 11 years in Shiraz and concluded that the prevalence of MIH was $20.2 \% .^{5}$ In 2016, Salem et al reported the prevalence of MIH to be $13.5 \%$ among children aged 6 to 13 years in rural areas of Masal and Shandman. ${ }^{11}$ However, in 2001, in a review study, Werhijm reported the prevalence of MIH in different populations to vary from 3.6 to $25 \% .^{12}$ Parikh et al. conducted a study on 1,366 Indian children aged 8 to 12 years and reported the prevalence of MIH to be $9.2 \% .{ }^{13} \mathrm{~A} \mathrm{UK}$ study in 2015 reported the prevalence of MIH to be $15.5 \% .^{14}$ This study was conducted by Balmer et al.

The differences observed in the prevalence of $\mathrm{MIH}$ in different studies appear to be due to age differences, ethnic and racial differences, geographical differences, environmental factors, MIH evaluation criteria, and participants' inclusion and exclusion criteria.6,15 Studies conducted on European populations have reported the prevalence of MIH to be $10 \%$ among the Swedish and the Dutch, $6 \%$ among the German, $16 \%$ among the Italian, $5 \%$ among the Bulgarian, and $28 \%$ among the Danish, while its prevalence in African countries such as Kenya, Libya and Hong Kong, and Brazil is reported to be $14 \%, 3 \%$, and $40 \%$ respectively. ${ }^{11}$

The results also showed that there was no significant difference in MIH of two sexes. This finding is similar to the findings of Ahmadi and studies conducted about Jordan, Spain, Singapore, Nigeria.6,16-20 On the contrary, in other studies the prevalence and severity of MIH was reported to be different in two sexes. ${ }^{16,21}$ This study attributed this difference to the inconsistency of dental crown completion, tooth eruption, and oral hygiene in both boys and girls. ${ }^{19,21}$ The results also showed that there is no significant difference in MIH based on parental education and family income; this result is consistent with the studies of Salem et al., Costa, Boindi, Muratbegovic, Sonmez, Jeremias, Arrow.7,11,15,22-24 One of the main goals of this study was to determine the probable predictive factors (pre- and postnatal factors) of MIH. For this purpose, significant variables in Fisher's exact test were entered into logistic regression and the results showed that only asthma / bronchitis variables, history of hospitalization and fever above 38.5 degrees $\mathrm{C}$ may be effective factors in $\mathrm{MIH}$.

Tourino et al's study (2016) on 1181 Brazilian children showed that children who experienced asthma and bronchitis in the first four years of their life were $1.45-2.56 \%$ more likely 
to be affected by MIH than normal children. ${ }^{4}$ Any infection, especially respiratory tract infection, such as the common cold, can cause frequent high fever (fever more than 5 times during the first year of life is considered as recurrent childhood fever). Stable high fever causes improper orientation of enamel prisms and crystal-free regions.8,25,26

Seizures are also a common cause of MIH in children. Febrile seizures are called high fever seizures and are thus linked to the prevalence of MIH. Fever-induced seizures are also associated with neonatal hypocalcemia. ${ }^{8,27}$ The results of this study are in line with those of Tourino et al. (2016); Lygidakis et al. (2008); Ghanim et al. (2013); Alaluusua et al. (2010); Pitiphat et al. (2014); Souza et al. (2012).8,28-30 In these studies, researchers identified asthma / bronchitis, hospitalization history, and fever above 38.5 degrees as MIH predictive variables. However, the results of this study showed that preeclampsia, medicine consumed to prevent premature labor, acetaminophen, premature birth, oxygen device without intubation, duration of breastfeeding, pneumonia, use of antibiotics and analgesics, asthma medications are not among the factors affecting the MIH among 8-10-year-old children in Ardabil. Previous related studies have shown that these factors have an influence on MIH.3,4,6,23,28,29,31-34 The difference between the results of this study and those mentioned can be attributed to differences in the statistical population, race, age of children, inclusion and exclusion criteria. Lack of specific causation in the incidence of MIH may also reinforce the possibility of genetic influence on lesions. For this reason, differences in factors affecting MIH may also be related to differences in genetics of Iranian ethnic groups, although broader epidemiological studies of genetics and homogenization of research methods across different parts of the country are needed to confirm this hypothesis. ${ }^{9,18,19,35}$ This is also statistically debatable; one of the recently published papers suggested a minimum sample size of 300 to investigate the prevalence of $\mathrm{MIH}$ and 1000 to investigate the aetiology. ${ }^{36}$ Considering the sample size of the present study, the method proposed by the European Academy of Paediatric Dentistry (EAPD) and cluster sampling method covering all community groups, it seems that the results of this study (prevalence of $\mathrm{MIH}$ ) can be generalized to all children aged $8-10$ years old in Ardabil, but it requires more than 1,000 children to investigate its aetiological factors, so further studies with larger samples are recommended. Various aetiologic factors have also been proposed in relation to the incidence of $\mathrm{MIH}$, however, a precise relationship has not yet been established between these factors and the incidence of lesions. It seems that it is necessary to do a research on the molecular mechanisms that cause abnormal function of ameloblasts to obtain deeper information on MIH lesion, although the genetic context of this lesion cannot be ignored. ${ }^{37}$

\section{CONCLUSIONS}

Considering the aforementioned cases, it seems that exposure to $\mathrm{MIH}$ cases requires extensive and multidisciplinary evaluation of the patient's condition, and long-term follow-up of treatments, and even their reformation. Overall, it seems that MIH is caused by a variety of factors.
Data sharing statement provided by the authors is available with the full text of this article at jemds.com.

Disclosure forms provided by the authors are available with the full text of this article at jemds.com.

This study is an extract of a thesis No. 140 with code of ethics IR.ARUMS.REC.1397.269,

All authors report grants from Ardabil University of Medical Sciences.

\section{REFERENCES}

[1] Weerheijm KL, Duggal $M$, Mejàre $I$, et al. Judgement criteria for Molar Incisor Hypomincralisation (MIH) in epidemiologic studies: a summary of the European meeting on MIH held in Athens. Eur J Paediatr Dent 2003;4(3):110-3.

[2] Gonçalves FBDS. Hipomineralização Incisivo-molar: prevalência e etiologia. [Doctoral dissertation, [sn]] 2011.

[3] Cho SY, Ki Y, Chu V. Molar incisor hypomineralization in Hong Kong Chinese children. Int J Paediatr Dent 2008;18(5):348-52.

[4] Tourino LFPG, Corrêa-Faria P, Ferreira RC, et al. Association between molar incisor hypomineralization in schoolchildren and both prenatal and postnatal factors: a population-based study. PloS One 2016;11(6):e0156332.

[5] Ghanim A, Manton D, Bailey D, et al. Risk factors in the occurrence of molar-incisor hypomineralization amongst a group of Iraqi children. Int J Paediatr Dent 2013;23(3):197-206.

[6] Ahmadi R, Ramazani N, Nourinasab R. Molar incisor hypomineralization: a study of prevalence and aetiology in a group of Iranian children. Iran J Pediatr 2012;22(2):245-51.

[7] da Costa-Silva CM, Jeremias F, de Souza JF, et al. Molar incisor hypomineralization: prevalence, severity and clinical consequences in Brazilian children. Int J Paediatr Dent 2010;20(6):426-34.

[8] Lygidakis NA, Dimou G, Marinou D. Molar-incisorhypomineralisation (MIH). A retrospective clinical study in Greek children. II. Possible medical aetiological factors. Eur Arch Paediatr Dent 2008;9(4):207-17.

[9] Vieira AR, Kup E. On the aetiology of molar-incisor hypomineralization. Caries Res 2016;50(2):166-9.

[10] Jälevik B, Norén JG, Klingberg G, et al. Etiologic factors influencing the prevalence of demarcated opacities in permanent first molars in a group of Swedish children. Eur J Oral Sci 2001;109(4):230-4.

[11] Salem K, Azizi D, Asadi M. Molar-incisor Hypomineralization in Masal-Shanderman, Guilan. Iran J Pediatr 2016;11(2):61-76.

[12] Weerheijm K, Jalevik B, Alaluusua S. Molar-incisor hypomineralisation. Caries Res 2001;35(5):390-1.

[13] Parikh D, Ganesh M, Bhaskar V. Prevalence and characteristics of molar incisor hypomineralisation (MIH) in the child population residing in Gandhinagar, Gujarat, India. Eur Arch Paediatr Dent 2012;13(1):21-6.

[14] Balmer R, Toumba K, Munyombwe T, et al. The prevalence of incisor hypomineralisation and its relationship with the prevalence of molar incisor hypomineralisation. Eur J Paediatr Dent 2015;16(3):265-9. 
[15] Sönmez H, Yıldırım G, Bezgin T. Putative factors associated with molar incisor hypomineralisation: an epidemiological study. Eur Arch Paediatr Dent 2013;14(6):375-80.

[16] Salem K, Aziz D, Asadi M. Prevalence and predictors of Molar Incisor Hypomineralization (MIH) among rural children in Northern Iran. Iran J Public Health 2016;45(11):1528-30.

[17] Zawaideh F, Al-Jundi SH, Al-Jaljoli M. Molar incisor hypomineralisation: prevalence in Jordanian children and clinical characteristics. Eur Arch Paediatr Dent 2011;12(1):31-6.

[18] Garcia-Margarit M, Catalá-Pizarro M, Montiel-Company JM, et al. Epidemiologic study of molar-incisor hypomineralization in 8-year-old Spanish children. Int J Paediatr Dent 2014;24(1):14-22.

[19] Ng JJ, Eu OC, Nair R, et al. Prevalence of molar incisor hypomineralization $(\mathrm{MIH})$ in Singaporean children. Int J Paediatr Dent 2015;25(2):73-8.

[20] Oyedele TA, Folayan MO, Adekoya-Sofowora CA, et al. Prevalence, pattern and severity of molar incisor hypomineralisation in 8-to 10-year-old school children in Ile-Ife, Nigeria. Eur J Paediatr Dent 2015;16(3):277-82.

[21] Ghanim A, Bagheri R, Golkari A, et al. Molar-incisor hypomineralisation: a prevalence study amongst primary schoolchildren of Shiraz, Iran. Eur Arch Paediatr Dent 2014;15(2):75-82.

[22] Muratbegovic A, Markovic N, Selimovic MG. Molar incisor hypomineralisation in Bosnia and Herzegovina: aaetiology and clinical consequences in medium caries activity population. Eur Arch Paediatr Dent 2007;8(4):189-94.

[23] Jeremias F, de Souza JF, de Costa Silva CM, et al. Dental caries experience and molar-incisor hypomineralization. Acta Odontol Scand 2013;71(3-4):870-6.

[24] Arrow P. Risk factors in the occurrence of enamel defects of the first permanent molars among schoolchildren in Western Australia. Community Dent Oral Epidemiol 2009;37(5):405-15.

[25] Kliegman RM, Behrman RE, Jenson HB, et al. Nelson textbook of pediatrics. Elsevier Health Sciences 2007.

[26] Tung K, Fujita H, Yamashita Y, et al. Effect of turpentineinduced fever during the enamel formation of rat incisor. Arch Oral Biol 2006;51(6):464-70.
[27] Scarfone RJ, Pond K, Thompson K, et al. Utility of laboratory testing for infants with seizures. Pediatr Emerg Care 2000;16(5):309-12.

[28] Alaluusua S. Aaetiology of molar-incisor hypomineralisation: a systematic review. Eur J Paediatr Dent 2010;11(2):53-8.

[29] Pitiphat W, Luangchaichaweng S, Pungchanchaikul P, et al. Factors associated with molar incisor hypomineralization in Thai children. Eur J Oral Sci 2014;122(4):265-70.

[30] Souza JF, Costa-Silva CM, Jeremias F, et al. Molar incisor hypomineralisation: possible aetiological factors in children from urban and rural areas. Eur Arch Paediatr Dent 2012;13(4):164-70.

[31] Weerheijm KL, Mejàre I. Molar incisor hypomineralization: a questionnaire inventory of its occurrence in member countries of the European Academy of Paediatric Dentistry (EAPD). Int J Paediatr Dent 2003;13(6):411-6.

[32] Petrou MA, Giraki M, Bissar AR, et al. Prevalence of molarincisor-hypomineralisation among school children in four German cities. Int J Paediatr Dent 2014;24(6):43440.

[33] Brogårdh-Roth S, Matsson L, Klingberg G. Molar-incisor hypomineralization and oral hygiene in 10-to-12-yr-old Swedish children born preterm. Eur J Oral Sci 2011;119(1):33-9.

[34] Crombie F, Manton D, Kilpatrick N. Aaetiology of molarincisor hypomineralization: a critical review. Int J Paediatr Dent 2009;19(2):73-83.

[35] Sidaly R, Schmalfuss A, Skaare AB, et al. Five-minute Apgar score $\leq 5$ and molar incisor hypomineralisation (MIH) - a case control study. BMC Oral Health 2017;17(1):25.

[36] Elfrink MEC, Ghanim A, Manton DJ, et al. Standardised studies on molar incisor hypomineralisation (MIH) and hypomineralised second primary molars (HSPM): a need. Eur Arch Paediatr Dent 2015;16(3):247-55.

[37] Kühnisch J, Thiering E, Heitmüller D, et al. Genome-wide association study (GWAS) for molar-incisor hypomineralization (MIH). Clin Oral Investig 2014;18(2):677-82. 